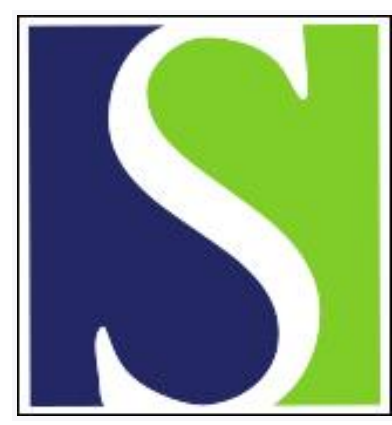

Scand J Work Environ Health 2008;34(3):189-197

https://doi.org/10.5271/sjweh.1241

Issue date: 30 Jun 2008

Occupational physicians' perceived value of evidence-based medicine intervention in enhancing their professional performance

by Hugenholtz NIR, Schaafsma FG, Schreinemakers JF, van Dijk FJH, Nieuwenhuijsen $\mathrm{K}$

Affiliation: Coronel Institute of Occupational Health, Academic Medical Center, PO Box 22700, NL-1100 DE Amsterdam, Netherlands. n.i.hugenholtz@amc.uva.nl

Key terms: intervention; evidence-based intervention; evidence-based medicine; interview; occupational health; occupational physician; perceived value; professional performance; professionalism

This article in PubMed: www.ncbi.nlm.nih.gov/pubmed/18728908

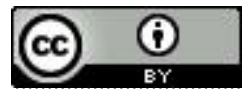




\title{
Occupational physicians' perceived value of evidence-based medicine intervention in enhancing their professional performance
}

\author{
by Nathalie IR Hugenholtz, MSc, ${ }^{1}$ Frederieke G Schaafsma, PhD, ${ }^{1}$ Jos F Schreinemakers, PhD, ${ }^{2}$ Frank JH \\ van Dijk, PhD, ${ }^{1}$ Karen Nieuwenhuijsen, $P h D^{1}$
}

\begin{abstract}
Hugenholtz NIR, Schaafsma FG, Schreinemakers JF, van Dijk FJH, Nieuwenhuijsen K. Occupational physicians' perceived value of evidence-based medicine intervention in enhancing their professional performance. Scand $J$ Work Environ Health. 2008;34(3):189-197.
\end{abstract}

\begin{abstract}
Objectives This study evaluated how physicians in a nonclinical setting perceive the value of an intervention with multifaceted evidence-based medicine with regard to enhancing their professional performance.

Methods A qualitative study was conducted using focus groups and face-to-face interviews with 14 of the 48 Dutch occupational physicians who participated in the intervention. The intervention combined a didactic course in evidence-based medicine with recurrent case-method learning sessions. During the sessions, the participants were challenged to discuss their cases and to give one another feedback on how to find information on cases.

Results Five main themes and four subthemes were identified: professional behavior and quality of care (subtheme: transparency): occupational physicians associated being up-to-date with quality of care, and evidencebased medicine was associated with improvements in professional standards; critical attitude and improved recommendations: occupational physicians asked themselves more-profound questions and searched more for information; sharing knowledge: the peer-group sessions facilitated the sharing of knowledge; communication (subthemes: colleagues, clients and other specialists): the more soundly based recommendations enhanced selfconfidence positively and therefore altered interaction with medical specialists in particular; and satisfaction and barriers: the occupational physicians were especially content with the structured discussion in the peer-group sessions. However, the intervention was very time consuming.

Conclusions The participants regarded the intervention as a useful method for enhancing their professional performance. They stated that they became more up-to-date and more self-confident by searching for and sharing knowledge. These actions resulted in more scientifically based recommendations and improved interaction with clients and other specialists. However, time constraints remain an important barrier.
\end{abstract}

Key terms interview; occupational health; professionalism.

The art of medicine is one of the oldest professions in the world. According to the definition of Freidson (1), professionals possess a body of special knowledge, they practice within an ethical framework, and they fulfill a broad societal need. Furthermore, professions have a social mandate that permits unrestricted autonomy in setting standards for education and the performance of their members (1).

In recent decades, changes in health sectors around the world have been affecting the professionalism of physicians (2-4). For instance, widespread access to the Internet enables patients to gain information on various health care topics and therefore makes the specialized body of knowledge less of an exclusive right for physicians (5). One of the most prominent effects of these trends has been a loss of autonomy and status by physicians, as it has become necessary for them to be clearer about what they do, as well as how and why they do it (6-8). Physicians perceive that this loss of autonomy and status affects their control over their professional lives, and this loss can be an important factor in job dissatisfaction among physicians (9-11).

By maintaining their body of specialized knowledge and striving to increase the accountability and

1 Coronel Institute of Occupational Health, Academic Medical Center/University of Amsterdam, Amsterdam, the Netherlands.

$2 \nmid 25$ May 2007; VU Faculty of Sciences, Department of Computer Science, Business Informatics Section, VU University, Amsterdam, the Netherlands..

Reprint requests to: NIR Hugenholtz, Coronel Institute of Occupational Health, Academic Medical Center, PO Box 22700, NL-1100 DE Amsterdam, Netherlands. [E-mail: n.i.hugenholtz@amc.uva.nl] 
transparency of their decisions, physicians are able to retain control over their work. Evidence-based medicine has been defined as "The conscientious, explicit, and judicious use of current best evidence in making decisions about the care of individual patients. The practice of evidence-based medicine requires the integration of individual clinical expertise with the best available external clinical evidence from systematic research and the patient's unique values and circumstances [p 1]" (12). During the last two decades, postgraduate training in evidence-based medicine has been studied both quantitatively and qualitatively in clinical and primary health care. Although physicians' knowledge of and attitude towards evidence-based medicine generally increases after training in evidence-based medicine, there is not much data available on whether it results in actual behavioral change in daily practice (13-18). However, integrating the teaching of evidence-based medicine into the routine practice of physicians has proved to result in positive outcomes (15). It offers physicians the challenge of practicing evidence-based medicine under the imperatives of "real-time" patient care (19). Furthermore, "integrated evidence-based medicine teaching" has resulted in treatment guidelines being more closely based on published evidence and in improvements in the care of patients (eg, more patients receiving therapies proved to be beneficial in randomized controlled trials $(14,20)$. In addition, using small group meetings has proved to be a useful framework for the integrated teaching of evidence-based medicine $(20,21)$.

Occupational physicians face even more difficulties in acquiring up-to-date knowledge in their field than physicians in other medical disciplines. Occupational physicians must also consider the work situations of their patients, management priorities, and legislation (22). Nevertheless, evidence-based medicine has the potential to be a feasible and useful method for occupational medicine that would enable occupational physicians to give more soundly based recommendations and secure their professional positions as providers of quality-assured information. In addition, the attitude of occupational physicians towards evidence-based medicine is positive, although most occupational physicians need substantial instruction and training to increase their searching and critical-appraisal skills (23-25). As the practice of evidence-based medicine is new for occupational health, no studies have yet been conducted on the effectiveness of training in evidence-based medicine in occupational health practice (26). Evaluation studies on its effectiveness are essential to determine if evidencebased medicine enhances the quality of occupational health care. In addition, there is a need for qualitative studies to explore occupational physicians' perceived value of practicing evidence-based medicine. This information is essential as support for the implementation of evidence-based medicine in occupational health care on a large scale.

Occupational physicians in the Netherlands have mostly an advisory role in striving to protect and improve the health of employees in relation to their work. Their main tasks concern evaluating fitness for work or vocational rehabilitation, both tasks generating the greatest demands for information (27). Results from a survey among Dutch occupational physicians have revealed that most of them make infrequent use of journals-a maximum of three times each month-and that they do not use practice guidelines very often. The status of occupational physicians is considered to be below that of general practitioners, and it should be enhanced by emphasizing professionalism among occupational physicians (28).

In order to support occupational physicians in this process by making more use of evidence, a multifaceted intervention was developed (appendix 1). The intervention was based on insights from research findings of postgraduate education in evidence-based medicine in the clinical setting and continuing medical education for physicians $(15,29)$.

It was assumed that the occupational physicians who participated in intervention with evidence-based medicine would benefit from the opportunity to acquire up-to-date knowledge and share their questions and professional expertise among peers. Since, until now, the impact of intervention with evidence-based medicine on the performance of occupational physicians has not been studied, we considered an exploration of the perceptions of occupational physicians regarding the value of the intervention as beneficial for a better understanding of the impact and the processes involved. Therefore, the central question of this paper concerns how the participating occupational physicians perceived the value of the intervention, special focus being centered on enhancing their professional performance.

\section{Material and methods}

As the objective of this study was to explore the perceptions of occupational physicians regarding the value of the intervention, the study design is qualitative. It was conducted within the context of a randomized controlled trial on the effectiveness of the intervention in enhancing the evidence-based practice of occupational physicians (30). Study participants were occupational physicians (some of whom were in training) who were working in the Netherlands. The participants were recruited through notices or contacts within the field of occupational health services and the Netherlands Society of 
Occupational Medicine. The physicians who applied to attend the program signed an informed consent form. After the intervention period, the occupational physicians from the intervention group were invited to participate in this qualitative study and to be interviewed by one of the researchers.

After the last session of each of the seven peer groups, one researcher (either NH or FS) guided a focus-group session with all of the participants present at the last session, which lasted approximately 30 minutes. Topics that were addressed in the focus groups were participants' experiences with the evidence-based medicine peer-group sessions in general, the kind of knowledge that was shared, whether they intended to continue with peer-group sessions in evidence-based medicine, and, if so, under what circumstances. The outcomes of these focus-group sessions provided a foundation for formulating the interview questions. The interview consisted of six main questions, each with a list of topics that were expected to come up during the interview (appendix 2). If these topics did not arise during the interview, the interviewer brought them up.

We conducted semi-structured interviews with a purposively selected subsample of 14 of the 48 occupational physicians participating in the intervention group between March and May 2006 (31). These occupational physicians had also taken part in the focus groups. We presumed that the occupational physicians who attended most of the sessions might be the most motivated physicians and would therefore have the most complete perceptions about the intervention. As the implementation of evidence-based medicine is relatively new in the occupational health field, we thought that they might be able to provide the best information on its impact and on opportunities and barriers for implementation. An additional argument was that we considered them as potential local opinion leaders who could successfully promote evidence-based practice. Therefore, knowledge about their perceptions could be crucial for progress (32).

The chair and one other participant from each of the seven peer groups were asked for permission to be interviewed. The physicians who were not the group chairs were selected according to the number of sessions in which they had participated. The occupational physician who had attended all of the sessions or who had attended the most sessions was invited for an interview. Since there were no major differences in age, years of experience as an occupational physician, or previous experience with evidence-based medicine, we took gender into account only in the sampling. If the chair was a man, and there were two or more occupational physicians (male and female) who attended a similar highest number of sessions, we selected a female and vice versa. Altogether, five female occupational physicians and nine male occupational physicians were interviewed.
Each face-to-face interview lasted between 30 and 45 minutes, and it was conducted in the respondent's consulting room during a workday. The interviewer gave a brief standard description of the purpose of the interview, explained that it was confidential, and asked for permission to audiotape the interview, with the assurance that the interview data would be erased within 3 weeks. All of the interview data were fully transcribed verbatim.

All of the transcribed interviews were subjected to analysis using MAXqda software (VERBI Software, Marburg, Germany, 2006). As the study was conducted within the context of a randomized control trial, we used a framework approach for the data analysis (33). The lead researcher $(\mathrm{NH})$ read and open-coded all of the transcripts. Another member of the research team $(\mathrm{KN})$ subsequently read and open-coded five transcripts independently of the first researcher. The two researchers then discussed their codes and reached a consensus on a single descriptive code set, resulting in eight descriptive codes. They then used this code set to code all of the interviews independently, thereafter discussing the coding of the interviews until consensus was reached. The coded text was then described in memos, which were subsequently analyzed. Categories and subcategories emerged as the analysis progressed. One of the researchers $(\mathrm{NH})$ then summarized the descriptively coded texts to reflect the essence of the description. These summaries were checked by a second researcher $(\mathrm{KN})$. Main themes and subthemes emerged during further analysis; a number of (sub)categories were grouped together and placed within or under these themes. This process ultimately yielded five main themes and four subthemes. Quotations (in italics) from the respondents $(\mathrm{R}+$ respondent number) illustrate the themes.

\section{Results}

\section{Professional behavior and quality of care}

The occupational physicians stated their opinions on professional behavior, quality of care, and the extent to which they had been influenced by the intervention. They associated being up-to-date with quality, and they thought that evidence-based medicine should be the current standard. The respondents also associated evidencebased medicine with both individual professionalism and the improvements in professional standards that are currently being demanded by both patients and employers. The incorporation of evidence-based medicine into daily practice is time consuming, however, and it can therefore be at odds with management requirements. The general opinion is that management should do more 
to facilitate the search for state-of-the-art knowledge, but that such searching is also the responsibility of the individual physician.

I also think that your professional stance should favor evidence-based practice, regardless of whether it is facilitated by your employer. The only way to profile yourself as an occupational physician is to be a good occupational physician and to have up-to-date knowledge (R115).

You know, every organization, including ours, is calling for quality. And I think, "Yeah, you can look at the $C V$, you can look at the further training and refresher courses, but whether an occupational physician is actually capable of acting according to the knowledge that you would expect ... that's another story". I have my doubts (R149).

\section{Transparency}

The participating physicians felt that they could not rely completely on information provided by their peers because most of it is based on personal experiences rather than on facts. Moreover, the physicians questioned the practice of their colleagues, stating that they are not always critical of their own performance. In general, performance is hard to assess because of the solitary way in which most occupational physicians work. The participants felt that the performance of their profession should be more closely monitored through some sort of auditing process. The peer-group sessions were seen as a possibility in this regard, and they considered them a quality instrument that could enhance the quality of performance.

You often hear, "Oh, that colleague knows all about lungs, so let's ask him what he thinks", as if that is the solution ... it could well be nothing but personal experience (R149).

Of course, those types are obviously less creative people-at least they are not very critical of their own actions. "Just leave me alone and let me do what I do; I've been doing this for years and there haven't been any problems" (R140).

\section{Critical attitude and improved recommendations}

The participants stated that the intervention resulted in a more critical attitude towards their practice. Becoming aware of the gaps in their knowledge enhanced their curiosity and their ability to ask themselves more profound questions. They were stimulated to look for more (background) information, and they found that this information contradicted their routine care.
(. . .) that was another point that emerged from my contributions. If I remember correctly, each of the five logbooks showed that I had followed a different policy, or at least a supplementary policy, in my practice that I wouldn't have used before (R140).

The participants reported that they had begun to search more and sooner for information in daily practice. They had also used evidence-based medicine to determine whether the information provided by their patients was correct or complete.

All of the participants believed that their recommendations had become more scientifically based, thereby enhancing their quality. Although most of the occupational physicians thought that the intervention had led them to make different recommendations, a few believed that their recommendations had not changed very much.

Because (. . .) you sit there in consultation the whole day, and people will sometimes say something, they sometimes claim something. They claim that they've read something or that they (. ..) that another doctor had made a statement, or they come with a condition or a disease, and they know something about it . . . then you sometimes think to yourself, "This doesn't make any sense at all" or "I have no idea what kind of condition that could be". You could go and look up something about a condition in a book, so to speak, but (. . .) it could be true, or the person could have heard it wrong. Well, in that case, I would think that I needed to check it out! Just on the Internet, on Google or in evidence-based medicine, for example. Just to see if there's something in the literature. Well, that works; it's a lot easier (R117).

\section{Sharing knowledge}

Prior to the intervention, not all of the participants were accustomed to sharing knowledge with colleagues. The intervention made some participants realize how seldom knowledge had been shared in the past. Although the sessions contributed much to the sharing of various kinds of knowledge and information among colleagues, search tips and results were the most common topics of discussion. During the meetings, the participants helped each other conduct searches.

By sharing their search results, the participants gained new knowledge and insights, they were stimulated to discuss clinical pictures, and they tried to develop a joint professional perspective.

(...) because everyone brings up different points, things that may be rare, or things that may be so common that you just stop thinking about them. So it does hold substantively for medical issues (R111). 
Then you also get new insights from others, other ways of interpretation (R123).

The participants also shared helpful websites, (electronic) guidelines from other specialists, and information from patient associations, as well as directions for interpreting evidence and integrating it into recommendations to clients.

\section{Communication}

Occupational physicians must deal with both patients and employers. They therefore consider patients, their supervisors, and management as their clients. The intervention changed the way physicians communicated with their colleagues (within the peer group, as well as outside), their clients, and other physicians.

\section{Colleagues}

Most of the participants were able to discuss their performance more profoundly after the intervention, and their contact with colleagues was more intense. They felt more critical towards each other, but, in a way, that stimulated cooperation.

And the nice thing about this type of project is that (. . .), the discussion and consultation with your colleagues can take place at another level (R149).

Our meetings and discussion were more lively and energetic because of the way we asked each other questions (. . .). Like a man suffering from tendinitis, and I reported it as an occupational disease, well, we were discussing it, and one colleague said: "But that is a quite unusual disease in the field of that occupation" and then we argued about it (R120).

\section{Clients}

Many occupational physicians became aware that it was necessary to inform patients that they had searched for information. They considered this approach useful, as many patients now tend to perform their own Internet searches for information. The patients appreciated that their occupational physicians had looked things up for them. This step often added much more openness and trust to their communication.

Fewer participants told the employers of their patients that they had sought information. When they did, however, the reactions of the employers were generally positive. Most of the occupational physicians noticed that they had become more secure in their communications with employers because of the intervention.
One thing I do notice is that I am now better at letting patients know that I'm up-to-date on things. That I am indeed a serious partner in the conversation, you know ... many patients have already surfed around on the Internet as well ... sometimes, they know more about it than I do, and that's not a bad thing, but it is sometimes a little embarrassing. I'm also able to suggest other sources, by ... actually just by following along through the links. (...) to let them know that I'm up to speed, and that gives them more trust, and hope, actually... (R153).

\section{Other specialists}

The participants experienced a great boost in confidence with regard to their communication with other specialists. They perceived that their communication with specialists had become more equal. They felt that they were taken more seriously, understood specialists better, and were better able to discuss the clinical problems of their clients with them. In some cases, this change led to changes in therapy.

And now I say, "Hey! We have a guideline" or "We have a treatment protocol" or "We know that this can work with this type of therapy". And it is adopted. And, after all, in maybe three of the ten cases that we discussed, medication was prescribed based on the discussion. That never happened before (R115).

It is rather nice to have contact that ... that is somewhat more equal in that respect (R123).

Despite these positive experiences, some participants also expressed reservations. A few participants felt that some specialists were not very happy with the betterfounded recommendations, and they assumed that the specialists considered such discussions as a threat to their authority. Changing the way of communicating with specialists was therefore not always considered appropriate.

I won't correct them, of course. Naturally, as an occupational physician, you don't often enter into debate with a specialist (R144).

Some of the participants had made changes in their written communication although it was considered harder to change. They improved the formulation of their questions and considerations, and they referred to their own guidelines or to evidence they had found through the intervention.

Now, if I think that something ought to be done, I write it up in a letter, adding why it ought to be done. And then I refer to a guideline or original research. And that helps (R115). 


\section{Satisfaction and barriers}

All of the participants enjoyed taking part in the intervention, and the group process was evaluated as particularly pleasant and valuable. In general, the occupational physicians were especially content with the structured discussions in the peer-group sessions. The obligation for each member to contribute to the discussion at each meeting was valued highly, as it prevented the meetings from being dominated by one person. The structure made it possible to raise many issues in a relatively short time, although a few participants would have preferred to have more time for presenting the cases. The method was also considered more suitable for relatively uncommon diseases, because of the existence of guidelines for the more common diseases.

The participants perceived that the peer-group sessions had enhanced their job satisfaction. The focus on medical issues was highly appreciated, as occupational physicians normally tend to discuss their attitudes and routines in meetings. It rekindled their curiosity and the need to study, which the participants enjoyed.

So I thought that everyone was equal and had a very open position in the process. And that was very stimulating. Everyone gets a turn, because you can say what you want to say in the piece that you've prepared. There's feedback on the right things. Yeah, that's great. Yeah, really informative, both the process and the results (R115).

The puzzling, the searching, something like, "Gee, what a question. How are you going to solve that?" and "What solution does that offer me?" Yeah, it is really a sort of puzzle, a question that you have, and you think, "Gee, how am I going to find that out?" so that you can move forward (R127).

The participants identified a number of barriers with regard to the meetings. Time constraints were the most frequently mentioned as a barrier to the realization and continuation of the meetings. Almost all of them had invested time after their usual workhours. The frequency of the meetings (every other week) posed the greatest obstacle, as it allowed too little time for preparation. Some participants considered the meetings too short to discuss all of the cases and logbooks. The presence of a competent chair who would keep track of the time was considered a necessity.

Two other important barriers to the continuation of the intervention were mentioned, the lack of technical support and the lack of skills in evidence-based medicine. During the intervention period, the participants were provided with full-text articles if they had no access to them. The lack of access to full-text articles was considered the main obstacle to continuation. Ac- cess to databases other than PubMed and the perceived lack of high-quality publications in the occupational health field, especially with regard to prognosis, was also perceived as an obstacle. The second barrier was that the participants still possessed limited skills in evidence-based medicine. Being able to provide a critical appraisal was considered the most difficult, as well as extrapolating findings to their own cases. They felt that they had made insufficient progress in these skills during the intervention period.

The fact that, as an occupational physician, you don't have as much access to the relevant databases is just a limitation . . . a deficiency. Because, you know (. . .) everything has a price, and the subscriptions do as well, but it wouldn't be too hard for the big occupational health and safety services to invest in them (R149).

\section{Discussion}

We hypothesized that the professionalism of occupational physicians could be improved by enhancing their body of specialized knowledge. An intervention was designed to help occupational physicians make better use of up-to-date knowledge in daily practice. The physicians who participated in this study valued the intervention, which consisted of a course in evidencebased medicine in combination with small-scale peergroup sessions, as a useful method for enhancing their professional performance. The physicians were of the opinion that they had become more up-to-date in their field, and this feeling boosted their autonomy and status, job satisfaction, self-confidence, and the interaction with clients and other specialists. However, the participants identified a number of barriers, time constraints being mentioned the most frequently.

To our knowledge, this study was the first to explore the perceived value of practicing evidence-based medicine with respect to the professional performance of occupational physicians. The occupational physicians' perceived usefulness of intervention with the use of evidence-based medicine is consistent with the outcome of the parallel randomized controlled trial that has shown that the intervention improved evidencebased recommendations by occupational physicians in sickness absence episodes (30). Shuval et al (17) found similar results in their qualitative study on the impact of an educational intervention using evidence-based medicine for primary care physicians. Like our study, this study was nested within a controlled trial, and the participants believed that evidence-based medicine enhanced the quality of their practice. The physicians also reported feelings of self-confidence when dealing with 
patients and pharmaceutical companies as a result of the intervention. In reference to Sandars \& Heller (34), opportunities for physicians to share and discuss their professional knowledge during peer-group sessions can improve the implementation of evidence-based medicine in the health care setting. Making more use of evidence in daily practice allows physicians to maintain control over the formal content of their work (35). It gives them the opportunity to recapture their autonomy and can protect against job dissatisfaction $(8,10,36)$. The fact that the physicians are able to discuss the medical content of their profession at a higher level seems to enhance their job satisfaction. Furthermore, the opportunity to meet regularly with peers, as in the peer-group sessions in the intervention, strengthens their relationships and enhances the intrinsically satisfying aspects of their work (37).

A common method used in qualitative research is to collect data from interviews until data saturation emerges, which determines the eventual number of participants (33). We interviewed a selected sample of 14 occupational physicians who participated in the intervention, and data saturation emerged at the 11th interview. However, because of the purposeful sampling, we decided to conduct and use all 14 interviews. By interviewing the selected sample of only occupational physicians who were considered to be the most motivated participants in the study, the representation of the perceived value of the intervention is biased. However, since these occupational physicians, pioneers in practicing evidence-based medicine, value evidencebased medicine as a useful method for enhancing their professional performance, they may become the opinion leaders to successfully promote evidence-based practice in occupational health. Hopefully their colleagues will regard them as "credible", "likeable", and "trustworthy"; then it is likely that they will be educationally influential. The most-motivated occupational physicians may play a key role in assisting others to become trained in evidence-based medicine (31).

However, major barriers to the adoption of the intervention were mentioned, including time constraints, limited access to full-text articles, lack of skills in evidence-based medicine, and a lack of management support. These barriers are the same as those found in previous studies among physicians outside the occupational health field $(14,15,18,38)$. The participants in our study expressed their concern about continuing to practice evidence-based medicine after the intervention period, as during the intervention access to full-text articles, and management support was provided. After the intervention, access to full-text articles will certainly disappear. Occupational physicians need a well-functioning knowledge infrastructure to access the evidence they need for practicing evidence-based medicine $(24,39)$.
Because time limitations form the most-difficult barrier to overcome in the implementation of evidencebased medicine, it can be argued that training experienced occupational physicians to become specialists in evidence-based medicine and training clinical librarians for occupational health would be helpful (40). Occupational physicians who are interested in evidence-based medicine can be facilitated by providing (advanced) courses in evidence-based medicine and the necessary facilities for information and communication technology, such as access to the Internet and to full-text articles, aids, and tools. In this way, they can assist other occupational health professionals to perform searches and to critically appraise articles. Furthermore, our study addresses only the impact of the intervention with evidence-based medicine on the self-reported behavioral changes of occupational physicians. There is still a need for an evaluation of data other than self-reports and an evaluation of the impact of physicians' use of evidencebased medicine on patient outcomes (41).

Finally, now that the occupational physicians had experienced the value of evidence-based medicine, they expressed the fact that they lacked a quality-assessment method for monitoring their own evidence-based practice and for auditing each other. Developing and implementing a quality-assessment method for evidence-based occupational health practice would be desirable in order to promote the quality of care provided by occupational physicians effectively.

\section{References}

1. Freidson E. Professional powers: a study of the institutionalization of formal knowledge. Chicago (IL): The University of Chicago Press; 1988.

2. Cruess SRM. Professionalism and medicine's social contract with society. Clin Orthop Relat R. 2006;449:170-6.

3. Bloom SW. Professionalism in the practice of medicine. Mt Sinai J Med. 2002;69(6):398

4. Blumenthal D. Doctors in a wired world: can professionalism survive connectivity? Milbank Q. 2002;80(3):525-46.

5. Gray NJ, Klein JD, Noyce PR, Sesselberg TS, Cantrill JA. Health information-seeking behaviour in adolescence: the place of the internet. Soc Sci Med. 2005;60(7):1467-78.

6. Grol R. Improving the quality of medical care: building bridges among professional pride, payer profit, and patient satisfaction. JAMA. 2001 28;286(20):2578-85.

7. Horton R. Medicine: the prosperity of virtue. Lancet. 2005;366(9502):1985-7.

8. Working Party of the Royal College of Physicians. Doctors in society: medical professionalism in a changing world. Clin Med. 2005; 5(6 Suppl 1):S5-40.

9. Edwards N, Kornacki MJ, Silversin J. Unhappy doctors: what are the causes and what can be done? BMJ. 2002;324:835-8.

10. Landon BE, Reschovsky J, Blumenthal D. Changes in career satisfaction among primary care and specialist physicians, 
1997-2001. JAMA. 2003;289(4):442-9.

11. Zuger A. Dissatisfaction with medical practice. N Engl J Med. 2004;350(1):69-75.

12. Straus SE, Richardson WS, Glasziou P, Haynes RB. Evidencebased medicine- how to practice and teach EBM. 3th ed. Edinburgh (United Kingdom): Elsevier; 2005.

13. McColl A, Smith H, White P, Field J. General practitioner's perceptions of the route to evidence-based medicine: a questionnaire survey. BMJ. 1998;316:361-5.

14. Straus SE, Ball C, Balcombe N, Sheldon J, McAlister FA. Teaching evidence-based medicine skills can change practice in a community hospital. J Gen Intern Med. 2005;20(4):3403.

15. Coomarasamy A, Khan KS. What is the evidence that postgraduate teaching in evidence based medicine changes anything?: a systematic review. BMJ. 2004;329(7473):1017.

16. Shuval K, Berkovits E, Netzer D, Hekselman I, Linn S, Brezis $\mathrm{M}$, Reis S. Evaluating the impact of an evidence-based medicine educational intervention on primary care doctors' attitudes, knowledge and clinical behaviour: a controlled trial and before and after study. J Eval Clin Pract. 2007;13(4):581-98.

17. Shuval K, Shachak A, Linn S, Brezis M, Feder-Bubis P, Reis $\mathrm{S}$. The impact of an evidence-based medicine educational intervention on primary care physicians: a qualitative study. $\mathrm{J}$ Gen Intern Med. 2007;22(3):327-31.

18. Hannes K, Leys M, Vermeire E, Aertgeerts B, Buntinx F, Depoorter AM. Implementing evidence-based medicine in general practice: a focus group based study. BMC Fam Pract. 2005;6(1):37.

19. Green ML. Evidence-based medicine training in graduate medical education: past, present and future. J Eval Clin Pract. 2000 May;6(2):121-38.

20. Lockwood D, Armstrong M, Grant A. Integrating evidence based medicine into routine clinical practice: seven years' experience at the Hospital for Tropical Diseases, London. BMJ. 2004 Oct 30;329(7473):1020-3.

21. Hunt DP, Haidet P, Coverdale JH, Richards B. The effect of using team learning in an evidence-based medicine course for medical students. Teach Learn Med. 2003 Spring;15(2):1319.

22. Lurie SG. Ethical dilemmas and professional roles in occupational medicine. Soc Sci Med. 1994;38(10):1367-74.

23. Carter T. The application of the methods of evidence-based practice to occupational health. Occup Med. 2000;50(4):2316.

24. Schaafsma F, Hulshof C, van Dijk F, Verbeek J. Information demands of occupational health physicians and their attitude towards evidence-based medicine [short communication]. Scand J Work Environ Health. 2004;30(4):327-30.

25. Verbeek JH, van Dijk FJ, Malmivaara A, Hulshof CT, Räsänen K, Kankaanpää EE, et al. Evidence-based medicine for occupational health [clinical question]. Scand J Work Environ Health. 2002;28(3):197-204.

26. Franco G. Evidence-based decision making in occupational health. Occup Med. 2005;55(1):1-2.
27. Schaafsma F, Hulshof C, de Boer A, Hackmann R, Roest N, van Dijk F. Occupational physicians: what are their questions in daily practice?: an observation study. Occup Med. 2006;56(3):191-8.

28. Noordam, de Vries. Contouren worden zichtbaar: positioneringsonderzoek NVAB [Contours are getting visible: position finding of the Netherlands Society of Occupational Medicine]. Amsterdam: Noordam \& De Vries: Adviesbureau voor organisatie en onderzoek; 2002.

29. Davis D, O'Brien MAT, Freemantle N, Wolf FM, Mazmanian P, Taylor-Vaisey A. Impact of formal continuing medical education: do conferences, workshops, rounds, and other traditional continuing education activities change physician behavior or health care outcomes? JAMA.1999;282(9):867-74.

30. Schaafsma F, Hugenholtz N, de Boer A, Smits P, Hulshof C, van Dijk F. Enhancing evidence-based advice of occupational health physicians. Scand J Work Environ Health. 2007;33(5):368-78.

31. Coyne IT. Sampling in qualitative research: purposeful and theoretical sampling; merging or clear boundaries? J Adv Nurs. 1997;26(3):623-30.

32. Doumit G, Gattellari M, Grimshaw J, O'Brien MA. Local opinion leaders: effects on professional practice and health care outcomes. Cochrane Database Syst Rev. 2007;(1): CD000125.

33. Pope C, Ziebland S, Mays N. Qualitative research in health care: analysing qualitative data. BMJ. 2000;320(7227):1146.

34. Sandars J, Heller R. Improving the implementation of evidence-based practice: a knowledge management perspective. J Eval Clin Pract. 2006;12(3):341-6.

35. Morris PWG, Crawford L, Hodgson D, Shepherd MM, Thomas J. Exploring the role of formal bodies of knowledge in defining a profession - the case of project management. Int J Proj Manag. 2006;24(8):710-21.

36. Timmermans S, Kolker ES. Evidence-based medicine and the reconfiguration of medical knowledge. J Health Soc Behav. 2004;45:177-93.

37. Brown S, Gunderman RBM. Viewpoint: enhancing the professional fulfillment of physicians. Acad Med. 2006;81(6):57782.

38. Forsetlund L, Bradley P, Forsen L, Nordheim L, Jamtvedt G, Bjørndal A. Randomised controlled trial of an theoretically grounded tailored intervention to diffuse evidence-based public health practice. BMC Med Educ. 2003;3:2.

39. Hugenholtz NIR, Schreinemakers JF, A-Tjak MA, van Dijk FJH. Knowledge infrastructure needed for occupational health. Ind Health. 2007;45(1):13-8.

40. Schwartz A, Millam G. A web-based library consult service for evidence-based medicine: technical development. BMC Med Inform Decis Mak. 2006;6:16.

41. Straus SE, Jones G. What has evidence based medicine done for us? BMJ. 2004;329(7473):987-8.

Received for publication 17 October 2007 


\section{Appendix 1}

\section{Description of the intervention with evidence-based medicine}

Occupational physicians in the intervention group received a course in evidence-based medicine lasting three half-days spread over 2 weeks. During this course, the physicians learned the following basics of evidencebased medicine: a general introduction to evidencebased medicine, instructions on searching for literature via PubMed, and techniques in critically appraising the literature. In addition, a member of each peer group volunteered to be the chairperson and received training in chairing case-method learning sessions.

Upon completion of the course in evidence-based medicine, the occupational physicians scheduled approximately 10 case-method learning sessions with their peer group (6-8 persons). These sessions took place every other week and lasted 1 to 1.5 hours. During these sessions, the occupational physicians were challenged to each discuss one case in a concise and structured format and to give one another feedback on how and where to find knowledge on the cases. At the end of a session, the occupational physicians chose a few cases (half of the total number of discussed cases) for which an evidence search was to be carried out by the respective occupational physicians. This search was conducted by means of the learned method in evidence-based medicine, using a logbook and guided by peers' feedback. The results of the search were presented briefly at the beginning of the next session.

During the intervention period, the occupational physicians had access to the Internet and to a helpdesk offering support in conducting literature searches and accessing full-text articles.

\section{Appendix 2}

\section{Interview questions}

1. What did you think of the case-method learning sessions?

2. What benefits have you realized from the case-method learning sessions?

3. To what extent have the case-method learning sessions changed your practice as an occupational physician?

Patient care

Policy

Quality

Professionalism

4. Do you feel that the case-method learning sessions have helped you to maintain your professional knowledge?
Searching
Evaluating
Sharing
Application
Type of knowledge
Learning

5. To what extent have the case-method learning sessions affected the contact that you have with your colleagues and other doctors, treatment specialists (or both)?

Have the case-method learning sessions affected you as a physician/professional?

As a physician, do you feel more confident about your professional knowledge?

Do you identify more positively with your profession?

Have the case-method learning sessions affected the pleasure that you experience in your work?

6. Were there factors that either facilitated or impeded the operation of the case-method learning sessions?

Impeding factors

Facilitating factors 